\title{
ChemComm
}

\section{A two-directional approach to pyrrolizidines: total syntheses and biological evaluation of alkaloid cis-223B and $( \pm)$-xenovenine $\dagger$}

Cite this: Chem. Commun., 2013
49, 10507

Received 5th September 2013, Accepted 27th September 2013

DOI: $10.1039 / c 3 c c 46800 c$

\author{
Alexandre Barthelme, ${ }^{* a}$ David Richards, ${ }^{b}$ Ian R. Mellor ${ }^{b}$ and Robert A. Stockman ${ }^{* a}$
}

www.rsc.org/chemcomm

Total syntheses of alkaloid cis-223B and xenovenine are reported in 3 and 4 steps respectively using a two-directional synthesis/triple reductive amination strategy, and their neurotoxic properties assessed.

Pyrrolizidine alkaloids (PAs) are widely present in nature. In plants they are produced as a defence mechanism against insect herbivores, where more than 650 PAs and PA $N$-oxides have been isolated from 6000 different species (REF). This class of alkaloids is also present in moths, ants and poisonous frogs. The occurrence in anuran skin was first reported in 1993 for a Bufonid (Melanophryniscus) toad. ${ }^{1}$ To date, 26 3,5-PAs including stereoisomers have been assigned to the class. These compounds display a broad range of biological activity, including glucosidase inhibition and anti-HIV potency, and can also play a necrotic and allergic role against living organisms, as they are used as chemical defence by batrachians. ${ }^{2}$ There are cases where the same alkaloids have been isolated in myrmicine ants, raising the hypothesis that the presence of some alkaloids in frogs could be caused by their dietary source in this case, illustrated by alkaloid cis-223H. ${ }^{1}$

In order to quickly access this class of molecules, we proposed a simple bio-inspired approach through a triple reductive amination. Starting from a triketone, we would form in one step 2 rings and 3 carbon-nitrogen bonds (Scheme 1). We surmised that the folded structure of the bicyclic system would enable us to attain the required stereochemistry by thermodynamic control.

Although there is no direct biomimetic proof of the supposed synthetic pathway for these pyrrolizidines, we inferred a similar mechanism to the one observed for alkaloid biosynthesis in ants and ladybirds. ${ }^{3}$ It has been particularly well documented in the case of coccinelline and precoccinelline. ${ }^{4}$

To explore our bio-inspired triple reductive amination strategy, two natural product targets were selected: the symmetrical alkaloid cis 223B 1, and non-symmetric ( \pm )-xenovenine 2 (Fig. 1).

\footnotetext{
${ }^{a}$ School of Chemistry, University of Nottingham, Nottingham, NG7 2RD, UK.

E-mail: Robert.stockman@nottingham.ac.uk

${ }^{b}$ School of Biology, University of Nottingham, Nottingham, NG7 2RD, UK

† Electronic supplementary information (ESI) available. See DOI: 10.1039/ c3cc $46800 \mathrm{c}$
}

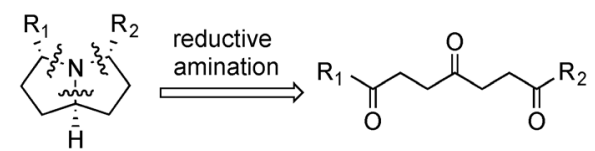

Scheme 1 Retrosynthetic analysis.

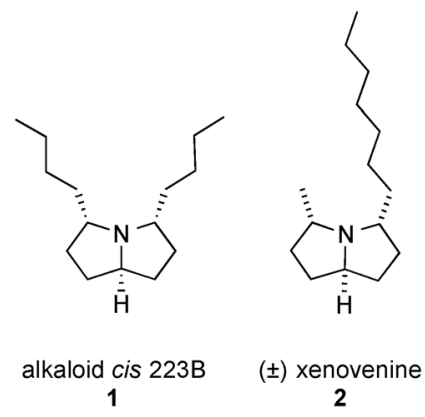

Fig. 1 Structures of alkaloid cis-223B and xenovenine.

We surmised that adaptation of our previous methods in twodirectional synthesis ${ }^{5}$ would be highly suited to the simple synthesis of the triketone precursors.

Alkaloid cis 223B contains two stereogenic centres. Its central planar symmetry provides a meso configuration. 1 was identified by GC-MS for the first time in 1989 in bufonid toads Melanophryniscus stelzneri (Argentina) and the frog Oophaga pumilio (Panama) but never was isolated. ${ }^{1,6}$ The first and only synthesis of alkaloid cis 223B was reported by our group in 2009: the latter was obtained in 7 steps and $43 \%$ overall yield. ${ }^{7}$ A synthesis of the trans configuration was later reported by Toyooka. ${ }^{8}( \pm)$-Xenovenine was isolated in 1980 from the venom of the ant species Solenopsis xenoveneum by Jones and co-workers. ${ }^{9}$ Structurally, this molecule is formed of a pyrrolizidine core with a 3,5-unsymmetrical substitution. Various syntheses of 2 have been published between 1986 and $2000 .{ }^{10}$ The biological properties of either compound have not been reported.

Using a two-directional approach, our initial synthesis started with the acetal protection of diethyl 4-oxopimelate 3 to the diester 4 (Scheme 2). The latter was then converted to Weinreb diamide 5. 


$$
100 \% \sqrt[\begin{array}{c}
\text { ethylene glyco } \\
\text { PPTS, toluene } \\
\text { reflux 12h } \\
\text { Dean-Stark }
\end{array}]{1}
$$
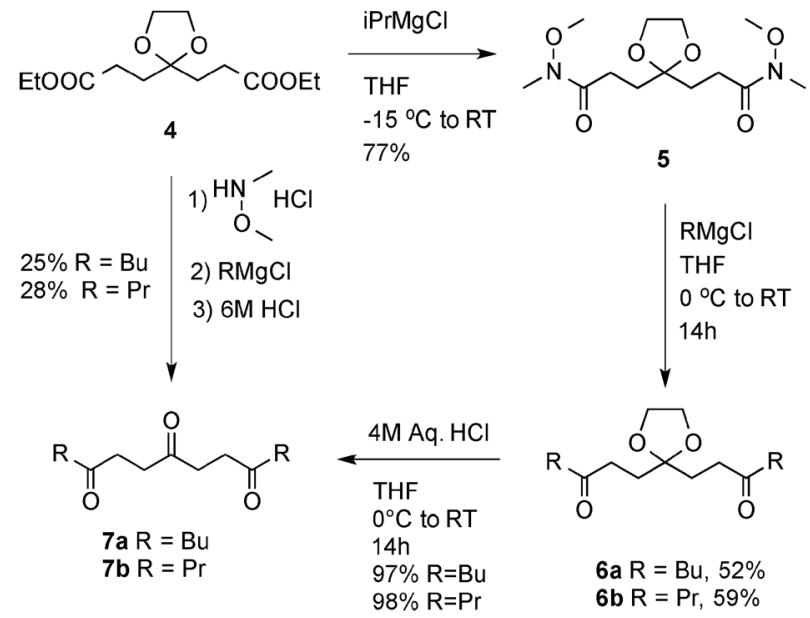

Scheme 2 Synthesis of cyclisation precursors.

The dialkylation of $\mathbf{5}$ with butylmagnesium bromide and subsequent deprotection of the central ketone gave access to the key triketone intermediate 7a in 4 linear steps and 39\% yield. The process was then later streamlined by simply allowing the deprotection to occur directly after the alkylation. A further development even allowed access to 7a directly from 4, enabling in one pot: diamide formation, dialkylation and acetal deprotection in $25 \%$ overall yield.

To convert the triketone precursors $7 \mathbf{a}$ and $7 \mathbf{b}$ to the corresponding alkaloid cis-223B and the bis C3-analogue 8, several reductive amination conditions were attempted (Table 1). Conditions were optimised for the precursor $\mathbf{7 b}$, with the best result obtained with 2 equivalents of sodium cyanoborohydride and 1.6 equivalents of ammonium acetate in methanol at $23{ }^{\circ} \mathrm{C}$ for 14 hours, giving a modest $29 \%$ yield of pyrrolizidine $\mathbf{8}$. These same conditions gave an improved $40 \%$ yield of alkaloid cis-223B when applied to the reaction of the longer chain triketone 7a. This increase in yield is likely down to the reduced volatility of the pyrrolizidine $\mathbf{1} v s .8$.

Having successfully demonstrated our two-directional approach for the synthesis of alkaloid cis-223B and chain-shortened analogue $\mathbf{8}$, we next turned our attention to the possibility of accessing nonsymmetrical pyrrolizidines. Using a sequential Grignard addition strategy to symmetric protected diamide $\mathbf{6}$, with addition of the longer chain first, followed by the methyl group, we were able to gain access to the non-symmetrical triketone 9 . The best isolated yield obtained for 9 after optimisation was $27 \%$ (Scheme 3). Our optimised conditions for the triple reductive cyclisation was then successfully applied to triketone 9, which, upon reaction gave $( \pm)$-xenovenine 2 as a single diasteroisomer in $24 \%$ yield. Jones reported a related triple reductive amination

\begin{tabular}{|c|c|c|c|c|c|}
\hline & $\begin{array}{l}\mathrm{n} \\
\mathrm{n}\end{array}$ & $\begin{array}{c}O \\
27 a \\
37 b\end{array}$ & $\stackrel{\text { conditions }}{\longrightarrow}$ & $\begin{array}{l}\sum_{\bar{H}}^{\sum_{n}^{-3 n}} \\
n=28 \\
n=31\end{array}$ & \\
\hline Entry & Solvent & Reagents/eq. & Temp./time & Product & Yield (\%) \\
\hline 1 & $\mathrm{MeOH}$ & $\begin{array}{l}\mathrm{NaBH}_{3} \mathrm{CN} 2.0 \\
\mathrm{NH}_{4} \mathrm{OAc} 1.6 \\
\mathrm{KOH} 0.2\end{array}$ & $\begin{array}{l}\text { RT } \\
14 \mathrm{~h}\end{array}$ & 8 & 13 \\
\hline 2 & $\mathrm{MeOH}$ & $\begin{array}{l}\mathrm{NaBH}_{3} \mathrm{CN} 2.0 \\
\mathrm{NH}_{4} \mathrm{OAc} 1.6\end{array}$ & $\begin{array}{l}\text { RT } \\
14 \mathrm{~h}\end{array}$ & 8 & Traces \\
\hline 3 & $\mathrm{MeOH}$ & $\begin{array}{l}\mathrm{NaBH}_{3} \mathrm{CN} 2.0 \\
\mathrm{NH}_{4} \mathrm{Cl} 1.6\end{array}$ & $\begin{array}{l}\text { RT } \\
14 \mathrm{~h}\end{array}$ & 8 & 29 \\
\hline 4 & THF & $\begin{array}{l}\mathrm{NaBH}(\mathrm{OAc})_{3} 3.0 \\
\mathrm{NH}_{4} \mathrm{OAc} 5.0 \\
\text { Cat. acetic acid }\end{array}$ & $\begin{array}{l}60{ }^{\circ} \mathrm{C} \\
1 \mathrm{~h}\end{array}$ & 8 & 25 \\
\hline 5 & EtOH & $\begin{array}{l}\mathrm{NH}_{3}-\text { EtOH } 5.0 \\
\text { Ti(OEt })_{4} 2.5 \\
\mathrm{NaBH}_{4} 1.5\end{array}$ & $\begin{array}{l}\text { RT } \\
14 \mathrm{~h}\end{array}$ & 8 & 7 \\
\hline 6 & $\mathrm{HCO}_{2} \mathrm{H}$ & $\mathrm{H}_{2} \mathrm{NCHO} 12.0$ & $\begin{array}{l}170{ }^{\circ} \mathrm{C} \\
4 \mathrm{~h}\end{array}$ & 8 & - \\
\hline 7 & $\mathrm{MeOH}$ & $\begin{array}{l}\mathrm{NaBH}_{3} \mathrm{CN} 2.0 \\
\mathrm{NH}_{4} \mathrm{OAc} 1.6\end{array}$ & $\begin{array}{l}\text { RT } \\
14 \mathrm{~h}\end{array}$ & 1 & 40 \\
\hline 8 & $\mathrm{MeOH}$ & $\begin{array}{l}\mathrm{Et}_{3} \mathrm{SiH} 2.0 \\
\mathrm{NH}_{4} \mathrm{OAc} 1.6\end{array}$ & $\begin{array}{l}\text { RT } \\
14 \mathrm{~h}\end{array}$ & 8 & - \\
\hline
\end{tabular}

Table 1 Optimisation of triple reductive amination of triketones

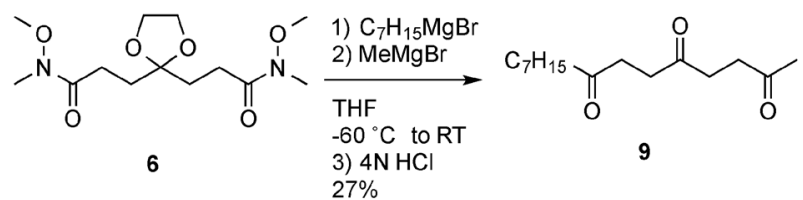

$24 \% \mid \begin{aligned} & \mathrm{NH}_{4} \mathrm{OAC} \\ & \mathrm{NaBH}_{3} \mathrm{CN} \\ & \mathrm{MeOH} \\ & \mathrm{RT}\end{aligned}$

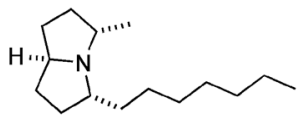

(士) xenovenine

2

Scheme 3 Synthesis of xenovenine.

in his report of the isolation of xenovenine, ${ }^{11}$ which gave a mixture of diastereomers. We were therefore particularly pleased to find that our optimised procedure gave the product as a single diastereomer.

PAs are known to be toxic to humans and other mammals ${ }^{12}$ as well as insects. ${ }^{13}$ Most studies have focussed on PAs isolated from plants, and information about animal derived PAs is limited. The main toxic activity of plant PAs appears to be hepatotoxicity, caused indirectly by pyrrole metabolites. ${ }^{11}$ Other alkaloids isolated from anurans are known to display neurotoxic activity by interacting directly with specific ion channels within the nervous system. One recognised target is the nicotinic acetylcholine receptor. ${ }^{14}$ Binding studies have shown that twelve of thirteen plant PAs tested do not bind competitively to neuronalnAChR, ${ }^{15}$ but a number of PAs isolated from anuran skin 

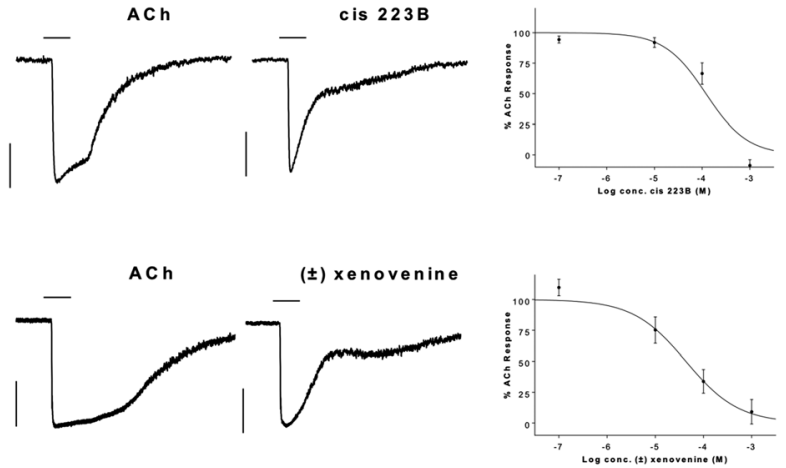

Fig. 2 Inhibition of ACh $(10 \mu \mathrm{M})$ induced currents in TE671 cells expressing human muscle-type nAChR by (a) cis 223B and (b) ( \pm )-xenovenine at $V_{\mathrm{h}}-75 \mathrm{mV}$. Typical traces showing ACh elicited currents (left) and when co-applied with pyrrolizidines $(100 \mu \mathrm{M})$ (centre). Vertical bars represent $200 \mathrm{pA}$ and horizontal bars show $1 \mathrm{~s}$ perfusion period. Concentration-inhibition plots fitted with nonlinear regression curves. The current at $1 \mathrm{~s}$ after onset (the point at which antagonism is greatest) was normalised against the preceding ACh only response at the same time point. Values represent mean \pm SEM for 5-12 cells.

display high affinity for Torpedo muscle-type nAChR. ${ }^{16}$ Spiropyrrolizidines are non-competitive antagonists of nAChR which display selectivity for neuronal over muscle-type receptors. ${ }^{17}$ Here we show inhibition of acetylcholine induced nAChR currents by cis-223B and ( \pm -xenovenine using patch-clamp of TE671 cells expressing human muscle-type nAChR. ${ }^{18}$ The results shown in Fig. 2 demonstrates clear, concentration dependent inhibition of the steady state current by both cis-223B and ( \pm )-xenovenine, with $\mathrm{IC}_{50}$ values of $120 \mu \mathrm{M}$ and $43.2 \mu \mathrm{M}$ respectively. Both compounds clearly inhibit the nicotinic acetylcholine response at high concentrations but the $\mathrm{IC}_{50}$ values generated are modest when compared with other alkaloids isolated from anuran skin. Spiropyrrolizidines are known to show selectivity for neuronal over muscle-type nAChR, ${ }^{16}$ and it is possible that this is also true of these compounds. Further investigation into the selectivity of these compounds for neuronal-nAChR and different sub-types thereof would reveal their potential as therapeutic leads for nAChR aberrations such as slow channel myasthenic syndrome.

In conclusion we have applied a bio-inspired cascade reductive amination methodology to the synthesis of alkaloid cis-223B 1 (3 steps, 10\% yield) and C3-analogue 8 (3 steps, $8 \%$ yield). This method was further developed to access unsymmetrical pyrrolizidine alkaloids, demonstrated by the diastereoselective synthesis of $( \pm$ )-xenovenine 2 in 4 steps and $5 \%$ overall yield. Despite the relatively modest overall yields (partially due to volatility of the products), these synthetic pathways remain by far the shortest syntheses described for $\mathbf{1}$ and $\mathbf{2}$, and demonstrate the overall effectiveness of the combined two-directional synthesistandem reaction strategy. ${ }^{19}$ The overall strategy should be applicable to a wide range of 3,5-disubstituted pyrrolizidines.
Furthermore, electrophysiology assays performed on nAChR from human muscle cells enabled us to determine the $\mathrm{IC}_{50} \mathrm{~S}$ of both natural products, confirming for the first time the suspected neurotoxic properties of these natural products.

University of Nottingham (AB), EPSRC (RAS, EP/E055346), Lawes Trust (DR) are acknowledged for funding.

\section{Notes and references}

1 M. Garraffo, T. F. Spande, J. W. Daly, A. Baldessari and E. G. Gros, J. Nat. Prod., 1993, 56, 357.

2 R. Liddell, Nat. Prod. Rep., 1998, 15, 363-370; N. Asano, R. J. Nash, R. J. Molyneux and G. W. J. Fleet, Tetrahedron: Asymmetry, 2000, 11, 1645.

3 G. King and J. Meinwald, Chem. Rev., 1996, 96, 1105-1122.

4 B. Tursch, J. C. Braekman, D. Daloze, C. Hootele, D. Losman, R. Karlsson and J. M. Pasteels, Tetrahedron Lett., 1973, 201; B. Tursch, D. Daloze, J. C. Braekman, C. Hootele and J. M. Pasteels, Tetrahedron, 1975, 31, 1541; W. A. Ayer and L. M. Browne, Heterocycles, 1977, 7, 685.

5 S. J. Roe, J.-C. Legeay, D. Robbins, P. Aggarwal and R. A. Stockman, Chem. Commun., 2009, 4399; A. F. Newton, S. J. Roe, J.-C. Legeay, P. Aggarwal, C. Gignoux, N. J. Birch, R. Nixon, M.-L. Alcaraz and R. A. Stockman, Org. Biomol. Chem., 2009, 7, 2274.

6 W. Daly, T. F. Spande and H. M. Garraffo, J. Nat. Prod., 2005, 68, 1556.

7 J.-C. Legeay, W. Lewis and R. A. Stockman, Chem. Commun., 2009, 2207.

8 N. Toyooka, D. J. Zhou, H. Nemoto, Y. Tezuka, S. Kadota, N. R. Andriamaharavo, H. M. Garraffo, T. F. Spande and J. W. Daly, J. Org. Chem., 2009, 74, 6784.

9 H. Jones, M. S. Blum, H. M. Fales and C. R. Thompson, J. Org. Chem., 1980, 45, 4778-4780.

10 D. Lathbury and T. Gallagher, J. Chem. Soc., Chem. Commun., 1986, 1017; T. Jiang and T. Livinghouse, Org. Lett., 2010, 12, 4271; H. Takahata, H. Bandoh and T. Momose, J. Org. Chem., 1992, 57, 4401; V. M. Arredondo, S. Tian, F. E. McDonald and T. J. Marks, J. Am. Chem. Soc., 1999, 121, 3633; X. K. Liu, X. Zheng, Y. P. Ruan, J. Ma and P. Q. Huang, Org. Biomol. Chem., 2012, 10, 1275.

11 H. Jones, R. J. Highet, A. W. Don and M. S. Blum, J. Org. Chem., 1986, 51, 2712.

12 S. Prakash, T. N. Pereira, P. E. B. Reilly and A. A. Seawright, Mutat. Res., 1999, 443, 53.

13 I. Narberhaus, V. Zintgraf and S. Dobler, Chemoecology, 2005, $15,121$.

14 H. Tsuneki, Y. You, N. Toyooka, S. Kagawa, S. Kobayashi, T. Sasaoka, H. Nemoto, I. Kimura and J. A. Dani, Mol. Pharmacol., 2004, 66, 1061; N. Toyooka, H. Tsuneki, S. Kobayashi, Z. Dejun, M. Kawasaki, I. Kimura, T. Sasaoka and H. Nemoto, Curr. Chem. Biol., 2007, 1, 97; X. Wang, H. Tsuneki, N. Urata, Y. Tezuka, T. Wada, T. Sasaoka, H. Sakai, R. A. Saporito and N. Toyooka, Eur. J. Org. Chem., 2012, 7082.

15 T. Schmeller, A. El-Shazly and M. Wink, J. Chem. Ecol., 1997, 23, 399. 16 H. Takahata, S. Takahashi, N. Azer, A. T. Eldefrawi and M. E. Eldefrawi, Bioorg. Med. Chem. Lett., 2000, 10, 1293.

17 B. Badio, D. Ski, Y. Shin, K. D. Hutchinson, W. L. Padgett and J. W. Daly, Biochem. Pharmacol., 1996, 52, 933.

18 T. Brior, I. R. Mellor, D. B. Tikhonov, I. Neagoe, Z. Shao, M. J. Brierley, K. Strømgaard, J. W. Jaroszewski, P. KrogsgaardLarsen and P. N. R. Usherwood, Mol. Pharmacol., 2003, 64, 954.

19 For other recent examples of this approach see: C. Gignoux, A. F. Newton, A. Barthelme, M.-L. Alcaraz and R. A. Stockman, Org. Biomol. Chem., 2012, 10, 67; D. Robbins, A. F. Newton, C. Gignoux, J.-C. Legeay, A. Sinclair, M. Rejzek, C. A. Laxon, S. K. Yalamanchili, W. Lewis, M. A. O'Connell and R. A. Stockman, Chem. Sci., 2011, 2, 2232. 